\title{
La otra cara de la felicidad: dolor y martirio en el peronismo clásico ${ }^{1}$
}

The other side of happiness: pain and martyrdom of classical peronism

Sandra Gayol

DOI: https://doi.org/10.24215/2314257Xe110

Universidad Nacional de General Sarmiento - CONICET,

Argentina

sandra.gayol@gmail.com

\section{RESUMEN:}

El artículo estudia el proceso de construcción del martirio de Eva Perón desde su aparición en el espacio político argentino hasta su muerte. Destaca el rol de Eva tanto como el de los "emprendedores morales" en la modelación del martirio y pone el foco en los valores y emociones que a través de él propiciaron tanto una comunidad emocional como una identidad política distintiva en la argentina contemporánea.

Palabras clave: Martirio, Comunidad emocional, Política argentina contemporánea.

\section{Abstract:}

The article studies the building process of Eva Peron's martyrdom from her appearance in the argentinean public space up until her death. It highlights the role of Eva, as well as that of the "moral entrepreneurs" in the modeling of martyrdom and puts the focus on values and emotions that through it fostered both an emotional community and distinctive politics in contemporary Argentina.

KEYWORDS: Martyrdom, Emotional community, Contemporary argentine politics.

"La felicidad de un descamisado vale más que mi propia vida"

Eva Perón, 1 de mayo de 1952

Unas semanas después, el 26 de julio, Eva murió. De la catarata de pronunciamientos que invadieron el espacio público de la Argentina fue la imagen de una mujer sacrificada por el bienestar de su pueblo la que predominó. El mensaje radial del secretario general de la Confederación General del Trabajo (CGT), José Espejo, que el mismo día de su muerte la proclamó "mártir del trabajo única e imperecedera en el movimiento obrero de nuestra querida patria”, inscribía a Eva en un panteón que se venía construyendo en el país desde mucho antes. Como en la mayoría de los países de Occidente, también en Argentina la figura del mártir fue apropiada y secularizada por el discurso político de la modernidad. Fueron definidos como mártires, por ejemplo, los trabajadores asesinados por el estado en la primera huelga general de 1902. También los obreros de la metalúrgica Vasena, en el barrio de Barracas de la ciudad de Buenos Aires, acribillados a balazos por la policía en 1919 por reclamar -huelga mediante- mejoras en las condiciones de trabajo y aumentos de salarios, o posteriormente las víctimas del terrorismo de estado de los años 70 del siglo pasado (Catoggio, 2013). Dos agrupaciones políticas competidoras del peronismo, la Unión Cívica Radical (UCR) y el Partido Socialista (PS), ya conmemoraban como mártires a los "caídos por sus causas" (Reyes, 2016). Estos panteones están integrados por individuos vinculados a organizaciones políticas o sindicales que fueron reprimidas por el estado. El sufrimiento físico culmina con la muerte violenta producida a causa de sus creencias y provocada por un tercero. Son los dirigentes, partidos políticos, movimientos sociales, algunos gobiernos, quienes ofician de "emprendedores morales" al postular y sostener en el decurso del tiempo, siempre post-mortem, a sus mártires que condensan los valores que se aspiran a imponer al grupo y/o los ciudadanos (Casquette, 2009; DeSoucey, Pozner \& Fileds, 2008; de Spiegeleer, 2014). 
No es el caso de Eva Perón, que murió a los 33 años a causa de un cáncer de útero cuando su marido, Juan Domingo Perón, era presidente de la nación y el hombre más poderoso de la Argentina. Ella misma era una pieza clave del peronismo, que tuvo la originalidad de albergar en su seno un doble liderazgo carismático, un líder y una líder complementarios uno del otro (Barry, 2009 p. 334). Más que oponerse a un régimen, Eva fue una de sus constructoras y devino su encarnación. A diferencia de otros movimientos políticos de masas del siglo XX, como el nacionalsocialismo en donde los mártires eran hombres, el peronismo enarboló su primera figura del mártir encarnándolo en el cuerpo de una mujer.

El peronismo, es sabido, decía de sí mismo que era el constructor de la "nueva Argentina”, y que trabajaba, especialmente sus dos líderes, para "que el pueblo sea cada día un poco más feliz". ${ }^{2}$ En un estudio hoy clásico, James subrayó el impacto "herético" del discurso peronista, que alentaba a los trabajadores excluidos y explotados a confrontar las jerarquías tradicionales. Una de las habilidades de Perón, insinuó el autor, fue apropiarse de la cultura de masas para conectarse con un público de clase trabajadora (James, 1990, pp. 37-38; 2004, p. 255). Más recientemente, Karush (2013) enfatizó que el lenguaje con el que Perón apelaba de manera tan potente a los trabajadores era esencialmente melodramático. En su moralismo maniqueo, en sus ataques a la codicia y al egoísmo de los ricos, y en su tendencia a presentar a los pobres como el auténtico pueblo argentino lleva rastros inconfundibles de las películas, la música y los programas de radio de los años treinta (p. 224). Un análisis que se detenga en las palabras, la voz y los gestos de Eva muestra esta deuda discursiva; permite avanzar en la semántica de estas palabras, recuperar otras emociones y descubrir interacciones con otras narrativas también disponibles en el campo cultural. Junto con el vocabulario del trabajo y la producción (Berhó, 2000), y con las invocaciones perennes al pobre virtuoso, noble y generoso, que diferentes trabajos han subrayado hubo importantes narrativas -verbales, gestuales y sonoras- del sacrificio, el amor y el dolor que no han sido suficientemente exploradas. Un análisis del martirio de Eva es una vía para reponer esta ausencia.

Si las políticas sociales del peronismo estuvieron a tono con las de la mayoría de los estados de Occidente de la época y en este sentido produjeron -hay consenso historiográfico- una "democratización del bienestar" (Torre y Pastoriza, 2002, p. 288), fueron también indisociables de un discurso estatal que no cesaba de recordar a la población la necesidad del esfuerzo y la abnegación. La utopía de una "patria feliz", en la que sus ciudadanos gozaban de derechos, deberes y beneficios antes impensados, tuvo como contracara la entrega y el sacrificio de sus líderes, y junto con ella se esperaba también la del pueblo trabajador de ser necesaria.

Además de un partido y organización política el peronismo era una "comunidad emocional". Las comunidades emocionales, si seguimos a Rosenwein (2010), son similares a las comunidades sociales de familias, vecinos, parlamentos, guildas, miembros de las iglesias parroquiales-, y en ellas se encuentran "sistemas de sentimientos". Estos "sistemas" representan lo que las comunidades (y los individuos que las integran) definen y consideran como significativo o peligroso para ellos, las evaluaciones que hacen de las emociones de los otros, la naturaleza de los lazos afectivos entre las gentes que reconocen, y los modos de expresión de las emociones que esperan, propician, toleran, deploran (Rosenwein, 2010, p. 11). ${ }^{3}$ Junto con la dignidad, el orgullo, la lealtad y el amor (James, 1990; Karush, 2013; Acha, 2013; Guy, 2016; Seveso, 2010), el discurso peronista fue indisociable del léxico y las experiencias del sacrificio, el dolor y el sufrimiento. Estas fueron emociones que alimentaron vínculos, legitimaron prácticas y nutrieron la comunicación emocional entre los ciudadanos y sus líderes, y entre aquellos.

Este artículo se interesa en el proceso de construcción social y política del martirio de Eva. En primer lugar argumento que la figura de la mártir fue la expresión radical de la compasión de Eva con el dolor de los desposeídos, los enfermos y los trabajadores, y que, a su turno, encarnó la humanidad del peronismo. En segundo lugar sostengo que el discurso del martirio que la propia Eva desplegó desde su temprano inicio en la actividad política remitía a situaciones concretas y, al mismo tiempo, legitimaba su propio liderazgo político. En tercer lugar argumento que los renunciamientos discursivos de Eva tuvieron eco en mujeres y hombres que se apropiaron de su léxico, lo articularon con sus experiencias particulares, lo enlazaron con experiencias 
colectivas y contribuyeron también así a modelar el discurso peronista. El amor, el dolor, el sacrificio como condición necesaria para la superación colectiva, la empatía y la felicidad fueron parte de una comunidad emocional específica a través de la cual se trazaba una distinción con otros espacios y actores del mundo social y político.

En el primer y segundo apartado pongo el foco en el proceso de autoglorificación desplegado por Eva, el cual es indisociable de su perfomance pública y que comenzó a tallar mucho antes de su enfermedad. Me apoyo en los discursos públicos que pronunció entre 1944 y $1952 .{ }^{4}$ Es un corpus de 285 textos de diferente extensión, pronunciados en ocasiones muy heterogéneas (en el congreso de estibadores rurales, en el acto de la unión de obreros municipales, mensajes de nochebuena), y en espacios y en soportes también muy disímiles (desde su lecho de enferma, en su despacho, en su domicilio particular, frente a una multitud en la avenida 9 de Julio, a través de la radio). Para sortear las diferencias entre los discursos conservados en papel y los registros grabados disponibles en el Archivo General de la Nación, me baso en mis propias transcripciones, y, para aquellos discursos que no fueron conservados en audio he multiplicado la consulta y cotejado entre distintas publicaciones. Me interesa comprender la semántica de las palabras diacrónica y sincrónicamente, los desplazamientos tanto como las persistencias de sentido. Me apoyo también en La razón de mi vida, libro firmado por Eva y publicado por primera vez en 1951.

En el tercer apartado buceo en la comunidad de actores que oficiaron de "emprendedores morales" del martirio. Es decir, me detengo en los hombres y mujeres que ante la inminencia de su muerte postularon, sostuvieron y buscaron imponer la figura de Eva mártir. Me interesa restituir los diferentes contextos de sus intervenciones discursivas, ver cuánto hay de repetición del léxico oficial y las posibilidades de apropiación que, a su turno, resignificaban el martirio. Pongo en valor especialmente las intervenciones en el Congreso de la Nación, junio y julio de 1952, disparadas en ocasión de convertir en ley el proyecto Monumento/Mausoleo a Eva Perón.

\section{"Política de las emociones"}

Desde la Revolución francesa el llamado emocional a las multitudes constituye uno de los utensilios retóricos favoritos entre las distintas fuerzas políticas. La política de masas del siglo XX profundizó esta situación y los ciudadanos fueron expuestos a una maraña de voces que usaban las emociones como recurso para intentar convencerlos, persuadirlos, "ganarlos" para una determinada orientación u agrupación política (Frevert, 2013). Qué emociones, cómo expresarlas, en qué contextos, hacia qué actores canalizarlas y hasta cuándo son preguntas que acompañan a todos los regímenes políticos y las relaciones de poder. Si bien Juan Perón solía repetir "nosotros construimos un movimiento al que se adhieren los hombres de cualquier parte que piensan y sienten como nosotros", 5 fue Eva quien lideró la "política de las emociones" 6 Es decir, fue ella quien apeló a un léxico emocional y a la generación de atmósferas, que a través de diferentes dispositivos de sensibilización, como sonidos, símbolos, rituales y prácticas situadas, transmitían y querían propiciar determinadas emociones. Como advierte Frevert, la política de las emociones no "tiene que ver con lo que realmente siente quien la realiza. Se trata de los 'recursos' lingüísticos y extralingüísticos que se emplean para transmitir y generar emociones, las 'emociones representadas' y su importancia para las 'técnicas del poder'" (Frevert, 2013, p, 5).

En la política de las emociones peronistas el amor ocupó un lugar central. El amor es una emoción política y también es la emoción social por excelencia. Si bien los soberanos ya habían apelado a él en el Antiguo Régimen -confesaban el amor que sentían por sus súbditos- y a su vez el amor a la patria ya había cimentado las "comunidades imaginadas" (Anderson, 2006) necesarias para la construcción de los estados nacionales decimonónicos, la política de masas del siglo XX y el capitalismo colocó al amor en el pedestal del consumo y de la afectividad (Illouz, 2012). La particularidad de Eva fue enlazar de manera explícita e interdependiente el ideal del amor romántico -sostén de su vínculo personal con Perón-con su discurso político y su actuación 
en el espacio público. En el siglo XX el amor romántico ofrece una utopía colectiva que atraviesa y trasciende todas las divisiones sociales. Su ideal está sustentado en el imaginario de la media naranja, el cual promueve, en el orden de la representación, la búsqueda del alma gemela que ha de asegurar la unión eterna entre los hombres y las mujeres (Illouz, 2012). Eva tuvo en Perón "su otra mitad", que la completa y ratifica en una intuición que, afirmó en La razón de mi vida, siempre la embargó: "la injusticia social no es ni natural ni lógica”. Su primer encuentro con quien será el hombre y una de las razones de su vida se dio en medio de una multitud y en el marco de una colecta para recaudar fondos para las víctimas del terremoto que devastó la ciudad de San Juan en enero de 1944. En este encuentro, que en La razón de mi vida fue tanto "su día maravilloso" como una revelación, habría dicho al general: "si como usted dice la causa del pueblo es su propia causa, por muy lejos que haya que ir en el sacrificio no dejaré de estar a su lado hasta desfallecer".

$\mathrm{Al}$ establecer la equivalencia entre su amor por Perón y su amor por el pueblo, "Evita produce el carácter único y natural del lazo entre Perón y el Pueblo" (Sigal y Verón, 2003, p. 208), y, agrego, entre ella y el pueblo. Los "hijos de los obreros son mis propios hijos y los hijos del Gral. Perón”, y por ello, como madre, ella es una fuente de nutrientes y una guía moral. El amor es una emoción imaginada como femenina que emerge no solo para explicar las experiencias amorosas de las mujeres con los hombres, sino también muchas iniciativas de aquellas en el espacio público. Eva hizo del amor un principio organizador de sus discursos, de sus interacciones con sus subordinados y de sus propias expectativas políticas. Como sostiene Nussbaum, las emociones no son simples impulsos, sino que incluyen valoraciones que tienen un contenido evaluativo, implican juicios y generan vínculos entre las personas (Nussbaum, 2014, p.19).

Eva comenzaba sus discursos con la frase "les traigo mi corazón” y se despedía de su auditorio con "al irme les dejo mi corazón”. El corazón es en la cultura occidental el símbolo de la pureza y de la fuente de donde emanan las emociones. En sus dos expresiones discursivas la líder de la política argentina ofrecía el órgano de la vida, de su vida, y les dejaba así lo mejor de ella misma. Del corazón emergía su amor. Como pasión, su amor podía ser ingobernable, perturbar su cuerpo y alimentar las críticas y acciones de sus opositores; como el afecto, su amor era su voluntad racional de proveer la felicidad del pueblo y al mismo tiempo era quien le mostraba la verdad.

El amor era como el don y era equivalente a la entrega total: "era darse y entregar su propia vida, recién entonces se está haciendo una obra de amor". 7 Era dar, recibir y retornar. Su amor hacia los trabajadores era reciprocado por el amor de los trabajadores hacia ella, reciprocidad que, en sus palabras: "la obliga a trabajar incansablemente y cuando los compañeros me dicen que me estoy gastando, pienso que me estoy gastando demasiado poco para un pueblo tan extraordinario como este". ${ }^{8}$

Si en los discursos de Perón el amor está presente, y si Eva decía -por ejemplo, en una de sus primeras alocuciones públicas transmitida por la radio del estado el 25 de julio de 1946- que Perón "sacrifica todo por la felicidad de su pueblo", es en ella - por su género y clase social- en quien el sacrificio por amor tiene más poder de enunciación. Como mujer, "sabe que las mujeres trabajan y luchan raudamente por su hogar", porque es mujer puede combinar exitosamente las lágrimas con la capacidad de contención; porque es mujer se involucra subjetivamente con el trabajo social; por su clase social decía: "he salido de las filas del pueblo trabajador (de ese pueblo) que se forjó en el dolor del taller y en el dolor del trabajo". Eva "siente las mismas inquietudes, sufre los mismos dolores" que su gente, y dado que es ella quien cotidianamente se vincula personal y emocionalmente con el pueblo es también la que más "sabe" de sus padecimientos, y más los "siente".

Estas expresiones, cuyas reminiscencias cristianas parecen obvias, eran también habituales en las formas de entretenimiento masivas de los años previos. La radio y el cine interpelaban a los pobres argentinos como el noble, largamente sufrido y auténtico pueblo (Karush, 2013), y Eva también había hecho del sufrimiento y la compenetración emocional con sus heroínas una clave interpretativa en sus programas de radio en 1944 (Sarlo, 2003). También se apropió de expresiones del saber médico. Ella "sabe" y "siente" porque, sostuvo, 
“auscultaba el corazón de los trabajadores”. Esta práctica médica ya usada en la política le permitía averiguar "todos los sinsabores de los descamisados".

Los militares que tomaron el gobierno de la Argentina en junio de 1943 denunciaron, junto con la corrupción política y económica, la inhumanidad del orden liberal previo. Perón, desde la Secretaría de Trabajo y Previsión y como vicepresidente, prometía saldar la deuda con las masas "sufridas y virtuosas" (Healey, 2012, p. 80). Fue a través de Eva y mediante Eva que el gobierno materializó su interés y compromiso con el dolor de los humildes.

Como sostiene Boddice (2014), el dolor es, en el mejor de los casos, una etiqueta confusa. Describe al mismo tiempo una apariencia o superficie, un estado interno -fisiológico y neurológico-, y la recepción de ambos tal como los proyecta otro (p. 4). Además de polivalente, el dolor es interpersonal. ${ }^{9}$ Eva no se limitó a nombrar el dolor, más importante, lo integró a su discurso político. Reconocer el dolor fue una práctica política pues enunciar cuál dolor es auténtico es una cuestión de poder (Bourke, 2014, p. 72). Eva se apodera y empodera los dolores populares pues oficia como uno de los dispositivos que, junto con las instituciones y leyes auspiciadas por el peronismo, sustentan, respaldan y propician conductas asociadas con "estar en dolor/ estar dolorido". ${ }^{10}$ En nombre de la Fundación Eva Perón, como se llamó a partir de 1948, recorría el país, se entrevistaba con dirigentes, "atendía los casos más diversos y a las personas más dispares". ${ }^{11}$ La fundación, el Partido Peronista Femenino y el vínculo permanente con la CGT fueron los pilares de la construcción y coronación de su liderazgo (Barry, 2009), y la traducción institucional de su compasión y, a su turno, de su martirio.

"Mitigar el dolor", como repitió sin cesar, connotaba dolores con lesión (enfermos, lisiados, minusválidos), dolores por las desigualdades materiales y dolores por las desigualdades sociales y simbólicas. En este conglomerado de situaciones, experiencias y contextos cobijados en la etiqueta del dolor residía, precisamente, su atractivo y eficacia política. Era el sufrimiento -sustantivo que también usó con frecuenciala fuente de su compasión y otro motor de sus acciones públicas. La compasión posee en ella los tres elementos cognitivos que señala Nussbaum: el juicio de la magnitud (a alguien le ha ocurrido algo malo y grave); el juicio del inmerecimiento (esa persona no ha provocado su propio sufrimiento), y un juicio eudaimonista (esa persona o esa criatura es un elemento valioso en mi esquema de objetivos y planes, y un fin en sí mismo cuyo bien debe ser promovido) (Nussbaum, 2008, p. 361). ${ }^{12}$ Sumará su inmolación.

Si la propaganda oficial la había identificado desde sus primeros días de primera dama con el trabajo incesante, fue a partir de 1948 cuando Eva empieza a hablar en nombre propio -y no solo en representación de Perón-, y a intervenir y solucionar conflictos laborales. Como afirmó por ejemplo al año siguiente: "trabajaba de sol a sol para llevar un poco de felicidad a los hogares humildes (y) en lugar de llevar una vida cómoda he optado por quemar mi vida en el despacho de Trabajo y Previsión". ${ }^{13}$ La expresión "quemar mi vida", memorable, muestra a Eva ardiendo tempranamente y reduciéndose lentamente a cenizas por subsanar el sufrimiento del pueblo trabajador.

El año 1949, cuando la pronunció por primera vez, fue muy importante para el peronismo y para Eva. Además de la creación del Partido Peronista Femenino (PPF), a inicios de ese año la Convención Constituyente aprobó la reforma de la constitución nacional que habilitó la reelección de Perón como presidente, incorporó los derechos políticos de la mujer, de los trabajadores, de los niños y de la ancianidad. La economía entró en crisis también ese año. El salario real cayó un $20 \%$ entre 1948 y 1952 y el déficit de la balanza comercial, la reducción de las divisas disponibles y la inflación eran muestras de que la intensa expansión del producto y del gasto que habían caracterizado el trienio anterior estaba llegando a su fin (Gerchunoff y Llach, 1998). En los más de cuarenta discursos que pronunció ese año Eva dialogó con esta coyuntura.

El 10 de enero de 1949 se reunió con secretarios gremiales, delegados sindicales y dirigentes obreros en la Secretaria de Trabajo y Previsión para "escuchar sus opiniones y coordinar ideas respecto al problema de la 
producción". En ese encuentro, en el que no se privó de advertirles sobre la necesidad de "prevenirse contra la acción de los comunistas que emplean la demagogia para provocar exigencias desmesuradas", ni de afirmar que "cada uno debe empezar a dar de sí todo lo que pueda dar y aún más”, remató con un llamado directo al sacrificio: "ha llegado la hora de que todos los dirigentes se sacrifiquen".

La palabra sacrificio proviene del latín sacro + facere, es decir, hacer sagradas las cosas, honrarlas, entregarlas y entregarse. Eva reclamó entregarse a la producción y renunciar a las demandas salariales. Es posible también que pidiera a los dirigentes que declinaran sus disputas y ambiciones políticas. La retórica marcada por el vocabulario del trabajo - construir, elaborar, emplear, producir, ganar- que Perón había usado para defender a los pobres y alcanzar la unidad nacional (Berhó, 2000) se extremó. El trabajo era el objetivo que debían tener los trabajadores. Incluso más, en su dimensión económica, el sacrificio era el trabajo incesante y el ahorro. Como también dijo en la misma intervención: "no podemos ir solamente en pos de conquistas materiales". ${ }^{14}$ Había que desterrar, continuó, "la teoría del menor esfuerzo". La ofrenda a la producción reclamada en palabras por la líder en prácticamente todas sus intervenciones de 1949 tuvo un correlato iconográfico. Como sostiene Gené (2005), la elusión del esfuerzo físico que signaba las representaciones de los trabajadores hacia 1948 cede terreno en las postrimerías del régimen a iconografías que, contrariamente, lo enfatizan (p. 91). No era un mero sacrificio personal. La novedad del peronismo en el poder consistió en que el Estado se ocupó de allanar el camino del ascenso social removiendo los obstáculos y ampliando los procesos que venían ocurriendo en la economía individual (Torre y Pastoriza, 2002, p. 278). El sacrificio pedido y esperado por Eva no implicaba una vuelta al pasado, no era solo una condición necesaria para la superación individual, sino una tarea de todos en pos de la felicidad colectiva. Se sostenía -al tiempo que se alimentabaen la red de relaciones sociales y afectivas propiciadas desde el gobierno. También importante, el todo incluía a los líderes. Eva no cesó de remitir y legitimar sus pedidos al sacrificio en sus propios renunciamientos.

El 10 de enero de 1949 decía:

A pesar de mi condición de mujer he elegido el camino más difícil y arduo, trabajando en esta Secretaría, enfrentando los mil problemas que en ella se plantean y atendiendo los casos más diversos y a las personas más dispares que por ella desfilan diariamente. Sin esos problemas mi vida sería mucho más tranquila, pero he elegido este camino porque quiero al movimiento que encabeza el General Perón y deseo que los demás no sufran ahora las miserias padecidas en épocas pasadas.

Una semana después en el acto organizado por el Sindicato Único de Ayudantes y Encargados de Casas de Rentas, en un teatro al aire libre en el barrio porteño de Palermo, repitió: "estoy poniendo mi vida, mi corazón y toda mi ternura de mujer argentina, para llevar la felicidad a todos los descamisados. Es la causa que he abrazado y por la cual daré hasta la última gota de mi sangre".

\section{CUERPO, VOZ Y AUTOSACRIFICIO}

El cuerpo del mártir es un símbolo reputacional concreto del sufrimiento (DeSoucey y Pozner \& Fileds, 2008, p. 112). También, agrego, la voz y los gestos son centrales al martirio. Eva, como sostiene Ehrick (2015), fue una imagen, pero también una voz. Los estragos de la enfermedad reforzaron el poder de la voz en su "política de las emociones" y en la edificación de su figura de mártir.

En su intervención del 22 de agosto de 1951, pero también en discursos previos y posteriores de ese año, con una voz monocorde y por momentos exhausta, la multitud que la aclamaba debió callarse para poder escucharla. Apenas audible ese 22 de agosto aseveró: "Mientras tanto ellos, los entreguistas, los mediocres, los cobardes, de noche tramaban la intriga y la infamia del día siguiente, yo, una humilde mujer, no pensaba sino en los dolores que tenía que mitigar y en la gente a la que tenía que consolar...”.

El 28 de septiembre de ese año el general Menéndez intentó dar un golpe de estado contra el gobierno. Sofocado por los militares leales a Perón, la CGT convocó a una multitudinaria movilización a la Plaza de Mayo en donde la ausencia de Eva no pasó inadvertida. Convaleciente de una operación, cuando se enteró 
por Perón de la intentona golpista, esa misma noche habló por la radio del estado y por la cadena nacional de radiodifusión. Los “jirones de su vida" se convirtieron en "jirones de mi salud, pero no de mi bandera”. Pidió a sus escuchas "con toda la fuerza de mi alma que sigan siendo felices con Perón, como hoy, hasta la muerte". Pidió que rogaran a Dios por su salud: "no para mí, sino para Perón y para ustedes, mis descamisados".

Es muy probable que la coyuntura política tan conflictiva propiciara la escucha de este discurso radial entre los seguidores, pero también entre los opositores. El censo nacional de 1947 mostró que había un aparato de radio cada dos viviendas lo que permite imaginar que la voz de Eva y de Perón podía llegar, y posiblemente ser escuchada, en los lugares más remotos de la argentina. Podría pensarse que también fue muy escuchado su mensaje radial del 7 de diciembre de 1951. En procura de interactuar con "sus compañeros y compañeras peronistas" mientras guardaba reposo por una operación, en este mensaje Eva les confiesa, con una voz difícil de reconocer, que su dolor le "ha hecho comprender más íntimamente el dolor de los demás (...) Antes yo solamente lo presentía y presintiéndolo me dediqué a aliviarlo en los cuerpos y en los corazones de los pobres y de los humildes". De no dolerse por sí misma, (en sus inicios había hecho suyo el dolor del pueblo), empezará públicamente a dolerse por su propia enfermedad y a incorporar su dolor físico y emocional como experiencia subjetiva significante y como móvil de sus acciones públicas.

Por las cartas enviadas a Eva sabemos que su voz "hechizaba" al auditorio (Guy, 2016). Entre 1944 y 1952 se pueden escuchar las transiciones en los tonos y timbres de su voz; es audible el pasaje de una voz que pudo ser cuestionada por demasiado aguda, hacia una más poderosa y firme, y más cuidada en su dicción, hasta desembocar en la voz exhausta de una moribunda que se despide y se exhibe ante su pueblo. La voz de Eva con las tecnologías de ampliación y grabación sonora (radio, fonógrafo, megáfono) fue clave para forjar una comunidad política que fue también una comunidad emocional. ${ }^{15}$ La voz femenina, su voz, es una dimensión clave de la política emocional del siglo XX, y Eva quizás sea uno de los ejemplos más ilustrativos. Como un todo orgánico - como palabra y gesto, significante y sonido, medio y mensaje (Ehrick, 2015)-, su voz adquirió más potencia aún en sus últimas intervenciones, en las que combinó de manera eficaz las técnicas de actuación, aprendidas durante su época de actriz, con el impacto de su enfermedad. Fue con una voz entrecortada por el llanto -en el mensaje radial del 7 de diciembre de 1951 que mencioné más arriba- que Eva entremezcló su sufrimiento por la enfermedad, su propia muerte, su vocación de morir por Perón y por los humildes, y su convicción de que también los humildes estaban dispuestos a morir por Perón. En este llamado al sacrificio político apeló a recursos lingüísticos y extralingüísticos que al tiempo que buscaban generar emociones le permitían, una vez más, "confesar" sus propias emociones:

recuerdo como si fuese una pesadilla de mi enfermedad la amargura del 28 de setiembre y tengo que agradecerles con toda mi alma lo que ustedes hicieron por Perón, rodeándolo para defender su vida o acaso para morir con él. Yo me acuerdo de que aquel día pensé: ya puedo morir tranquila, porque Perón tiene su vida bien guardada, porque cada peronista ha tomado como suyo mi propio trabajo de eterna vigía de la revolución.

Si desde 1947 sus discursos reclamaban a los trabajadores producción y a las mujeres colaboración en la economía del hogar, y en 1949 el llamado giró en torno a "producir, producir, producir" y a la renuncia de las mujeres a la ambición política (Barry, 2009), en 1951 el sacrificio remitirá a la muerte. Frente al enemigo que acecha la resistencia y la lucha es un deber. La excepcionalidad del sacrificio de Eva convertirá esa lucha, para todas y todos, en una obligación moral. A pesar de que hubiera podido hacerlo, como recordó una vez más en 1951, "no jugó al bridge con los oligarcas del Jockey Club"; de igual modo rechazó el "papel decorativo de la mujer del presidente, [y optó] por el papel de una mujer que, interpretando los dolores las ansias y las esperanzas del pueblo argentino, puso su corazón, su juventud y su vida al servicio de la causa de los que necesitaban de su esfuerzo". ${ }^{16}$

La muerte se descubre tempranamente como recurso de la política en la retórica peronista, y si Eva misma expresó, por ejemplo, en 1948, que "estaba dispuesta a morir contenta luchando por un hermoso ideal", sus discursos de 1951 y 1952 están plagados de referencias a la muerte, y coinciden, temporalmente, con sus 
SANDRA GAYOL. LA OTRA CARA de LA FELICIDAD: DOLOR Y MARTIRIO EN EL PERONISMO CLÁSICo ${ }^{1}$

cada vez más prolongadas internaciones. En este interregno pasó de estar dispuesta a morir a elegir morir. Así remató el 1 de mayo de 1951: "Y si a mí me dieran a elegir entre todas las cosas de la tierra, yo elegiría entre ellas la gracia infinita de morir por la causa de Perón, que es morir por ustedes”.

\section{"CAYó UN SOLDAdo EN SU PUESTO DE COMBATE"}

Esta frase, que el diario Democracia eligió para titular la muerte de Eva, es una expresión típica del martirio. Eva no se resistió a morir y en su última interacción con Perón, la noche previa a su muerte, habría pedido al general: "pase lo que pase, lo único que yo te pido es que no abandones nunca a los grasitas". ${ }^{17}$

El embellecimiento de su muerte se había echado a andar meses antes a través de descripciones que apuntaban a remarcar el escaso cuidado de sí misma (Navarro, 1997). El desdén hacia su persona -que Democracia radicalizó aseverando que no se había operado para poder participar de las elecciones de 1951 y que por ello, concluye, "decidió morir poco a poco"- subió de voltaje días antes de su muerte y desembocó sin tropiezos en el martirio.

La conocida misa impetratoria frente al obelisco de la ciudad de Buenos Aires seis días antes de su fallecimiento -en la que el padre Virgilio Filippo, en una necrológica anticipada, afirmó: "ahora, compañeros, ya tenemos nuestra mártir"- estuvo a tono con una miríada de publicaciones oficiales - por ejemplo, Mundo Peronista-, que estampaban en letra de molde, a la par de coloridas imágenes, transposiciones del evangelio y homologaciones entre Eva y la virgen María. Coherentes en el marco de un gobierno que desde 1950 buscaba profesar su propia variante de la religión católica oficial (Caimari, 1995), posiblemente ese discurso también se insertara con escasas tensiones en la tradición de religiosidad popular arraigada en la población y que otros dirigentes políticos ya habían usufructuado. La equiparación entre el mártir que se construye socialmente y el patrón maestro de construcción del mártir, Jesucristo, fue habitual en los movimientos políticos de masas del siglo XX y el peronismo no fue la excepción. Fueron especialmente "eclesiásticos quienes propusieron el paralelismo entre el calvario y la muerte de Jesucristo y el dolor sufrido por Eva” (Santos Lepera, 2012, p. 169).

La Eva apasionada por el dolor de los pobres, casta o asexuada, inspirada en el conglomerado de mártires cristianos, se insinuó también en maquetas y esculturas que ornamentarían el edificio que consagraría su memoria. Este proyecto monumento/mausoleo, ideado por el escultor León Tomassi y gestionado por la Comisión Pro-Monumento a Eva Perón, presidida por la senadora Juana Larrauri, se convirtió en la Ley 14.124 aprobada por el parlamento nacional. Si bien nunca se construyó, quienes estuvieron en el recinto fueron "emprendedores morales" claves del martirio de la líder. En el curso de junio y julio de 1952, y en el marco de la muerte inminente, legisladores peronistas trataron el proyecto. De los 135 diputados que componían la cámara parcialmente renovada en abril de 1952, 23 eran mujeres, y de los 112 hombres, 14 pertenecían a la UCR. De los 30 integrantes del Senado, 6 eran mujeres representantes del oficialismo (Barry, 2009). ${ }^{18}$

Las intervenciones no solo marcan claramente el pasaje de la automodelación a la construcción social del martirio, sino que fueron además un rito de pasaje en la política parlamentaria formal para las mujeres y también para algunos hombres, pues "fue por Eva que hablaron por primera vez en público". ${ }^{19}$ Juraron lealtad a Eva y Juan, aunque en los 19 discursos de las legisladoras Eva es el peronismo y ellas son sus representantes. ${ }^{20}$ En los discursos masculinos Eva es "coautora" y si en algunas participaciones se confunde con Perón tiende a prevalecer el "Perón presidente realizando una obra ciclópea que Eva afianza y asegura". ${ }^{21}$ Es evidente que en los discursos las mujeres y los hombres usaron frases arrancadas de declaraciones de Eva; se apropiaron de párrafos enteros de La Razón de mi vida; “jirones de su vida” (en clara referencia a "jirones de mi vida”) corrió como mancha de aceite en el recinto. Como mártir femenina Eva confluyó con mujeres "imprescindibles para la humanidad”. Catalina la Grande, Isabel de Inglaterra, Isabel de España, Encarnación Escurra y Juana Azurduy fueron el panteón híbrido que desde que ingresó, Eva lideró. 
En estas competencias oratorias se retoma, en forma de hipérbole, todo lo que ya se había escuchado y escrito sobre su sacrificio. Las sesiones se iniciaban con la escucha de la versión fonográfica del discurso de Perón del 17 de octubre de 1951. En este discurso Perón no solo le dedicó a su mujer la celebración que simbólicamente señalaba el nacimiento del peronismo, sino que su intervención se inscribió en una secuencia de gestos, palabras e imágenes (sostuvo a Eva varias veces cuando saludó a la multitud que vivaba su nombre, fue él quien le entregó la "gran medalla peronista", y ambos se fundieron en un abrazo público) que fueron la condensación política del amor personal de la pareja. Este abrazo, que la cámara de Pinélides Fusco eternizó, todavía hoy integra la memoria afectiva del peronismo. La reactualización parcial de este evento en el recinto parlamentario proseguía con vivas a Eva y Juan, con aplausos, en ocasiones se entonó la marcha peronista y también se desplegaron símbolos partidarios. Sin embargo, no celebraban solo a Eva ni se limitaban a ratificar su martirio. El $60 \%$ de los legisladores peronistas habló en el recinto. Una lectura secuencial de sus intervenciones muestra que también se celebraban a sí mismos rivalizando y compitiendo unos con otros a partir de sus destrezas y habilidades apologéticas hacia Eva. No hablaron solo de Eva. Cada referencia a esta entroncaba con experiencias individuales y se entremezclaba con una nueva biografía social y política que habría habilitado el peronismo.

"Surgido de las filas proletarias" y representante de Formosa, el diputado Mariño comparte en el recinto lo que

jamás podrá olvidar [y] que fue un día maravilloso (...) cuando una delegación de los territorios nacionales tuvo como mayor placer del mundo hablar con la señora Eva Perón (aplausos) a quien hasta ese momento, en honor a la verdad, era un sueño casi irrealizable para los habitantes territorianos de la patria verla, hablarla, estrechar su mano y contemplar de cerca su pura y franca faz. ${ }^{22}$

Si el encuentro con Eva fue el momento para la generación de su "experiencia inolvidable", el recinto parlamentario fue el espacio el en que ratificó a través de la repetición verbal las emociones que lo habían habitado en su interacción cara a cara. No eran meras palabras. Como propone Plamper (2014), estas expresiones pueden ser pensadas como "declaraciones de experiencias" o manifestaciones emocionales que pueden tener efectos concretos sobre el sentimiento vivido subjetivamente. Para el diputado por la capital Presta, la interacción con Eva también fue inseparable de intercambios emocionales que fueron experiencias cognitivas: "cuando ella habla o nos mira, nuestra mirada sorprendida queda detenida ante sus ojos, porque su mirar representa no solo ternura sino seguridad y aliento que lleva al triunfo". ${ }^{23}$ Estas intervenciones eran interrumpidas con aplausos, eran festejadas, vivadas por el auditorio. El tono de la enunciación, es decir, la forma de enunciar generó empatía. Al finalizar, el orador o la oradora era nuevamente aplaudido por sus pares; se abrazaban, felicitaban, cantaban, lloraban, aplaudían, se ponían de pie. Se sumaba al festejo el público agolpado en los balcones del recinto. Esto significa que tales demostraciones no se contentaban con permitir la expresión de las emociones; las inculcaban, las generan, las alimentaban. Eran prácticas que propiciaban la empatía y un "estar en sintonía" con el "pensar, hacer o actuar" del orador (Flatley, 2008). Más distantes de este clima emocional, pero atentos a sus derroteros, se situaban los integrantes de los consejos deliberantes, de las cámaras provinciales, los gobernadores, las cooperativas, que expresaron su adhesión mediante cartas que eran leídas, y aplaudidas, al inicio de cada sesión.

Las declaraciones de experiencias individuales se fundían discursivamente en declaraciones de experiencias colectivas. Apropiándose y parafraseando La Razón de mi vida el diputado por Buenos Aires, Tesorieri espetó: "también para nosotros el día más feliz de nuestras vidas es cuando unimos nuestros destinos al peronismo". ${ }^{24}$ La felicidad era por supuesto la "democratización del bienestar", que aparecía explícitamente enunciada y asociada con las leyes que "equiparaban derechos y deberes, (y) reconocían los sacrificios del pueblo". ${ }^{25}$ El reconocimiento al "pueblo trabajador, sufrido y heroico" ${ }^{26}$ empalmaba en el recinto con la acción redistributiva del gobierno y con el poder del estado para allanar el camino de la integración y la movilidad. Como ha sido señalado por la historiografía, este proceso de integración fue material y simbólico. 
La autoestima y la conciencia de pertenencia plena a una Argentina más igualitaria puso en crisis la deferencia y el respeto por el orden social preexistente (James, 1990) y también propició un quiebre del régimen emocional hegemónico. Como sostuvo Reddy (2001), el control de las emociones es central para cualquier régimen político estable, y, al mismo tiempo, las tensiones entre régimen emocional y la adecuación a él generan sufrimiento emocional. En su intervención quizás más aclamada -fue interrumpida cinco veces por sus pares-, la diputada por Salta Aguilar subrayó que el significado del peronismo "para el pobre, el descamisado, el obrero (...) el indio de los ingenios (...) la coya de los cerros (...) y las pastoras que cuidan los rebaños" había sido como un "sacudón eléctrico". Fue con esta bella metáfora que estalló el recinto. En su opinión la tormenta peronista desintegró las viejas jerarquías sociales y el régimen emocional hegemónico. La restitución de la honra desde el estado buscó borrar la humillación del pasado y "mitigar" el dolor que le es constitutivo. El autoritarismo había generado explotación económica, exclusión política, desprecio de clase y sufrimiento emocional. El legado peronista fue la supresión de estas formas de discriminación, la libertad de expresar ciertas emociones y una idea de justicia entendida como la igual valía de todos los ciudadanos y ciudadanas. ${ }^{27}$ El reconocimiento emocional más invocado, en sintonía con la mártir celebrada, fue el dolor. Los dirigentes del pasado -se escuchó reiteradamente en el parlamento argentino- no solo "traicionaban las promesas del pueblo, sino que también se burlaban de su dolor", ${ }^{28}$ y expresado con las mismas palabras que Eva había usado innumerables veces, "sufrimiento moral" por la humillación que les propinaba "la oligarquía”.

El dolor no existe independientemente de otras prácticas del yo: cognitivas, perceptivas, emocionales, evaluativas, que están entrelazadas con el contexto que respalda o desconoce conductas asociadas con "estar en dolor/estar dolorido" (Bourke, 2014). El pueblo sufriente venía siendo tematizado por la cultura de masas, encontraba ecos en el discurso del catolicismo social, y las secuelas de la segunda guerra y de las enfermedades degenerativas sobre los cuerpos estimularon y exigieron que los médicos se comprometieran con una aproximación más humanista del dolor (Bourke 2014; Testa, 2018). Es decir, en el discurso cultural del período la disposición empática hacia el dolor de los otros como cualidad moral era recurrente, pero el peronismo hizo de él una cualidad política. Al nombrar, incorporar de manera repetitiva y reconocer el dolor mediante palabras, gestos e instituciones específicas, el peronismo hizo del dolor una práctica política. En opinión de la diputada Dacunda, fue Eva quien "les enseñó que el peronismo es también una misión al servicio de los humildes y del sufriente" ${ }^{29}$ La compasión era una emoción distintiva de Eva -solo su "sensibilidad exquisita" le permitía hacer suyo y sentir en su propio cuerpo el dolor de los otros, pero la empatía entendida como la capacidad de percibir, comprender e identificarse con el sufrimiento ajeno aparecía como constitutiva y constituyente del discurso de estos "emprendedores morales" del martirio, y fue central en sus proceso de subjetivación política.

El proyecto monumento/mausoleo fue el último homenaje a la líder moribunda, y, como expresó sin sutilezas el diputado López por Jujuy, "fue también una expresión de fe y unión peronista". La fidelidad, creencia y unión peronista se articulaba en torno a la celebración de Eva y también a partir de ciertos valores y emociones que generaron un sentido de comunidad emocional y política con el peronismo. Ser parte de esta comunidad emocional era compartir normas y modos de expresión de las emociones. Era recolocar el amor, el orgullo, la dignidad y el dolor como emociones legitimadas en el espacio público y por el poder político. Es decir, no se trataba solo de nombrarlas sino también de involucrarlas en las respuestas y en las interacciones sociales y políticas.

\section{CONSIDERACIONES FINALES}

La reconstrucción del martirio de Eva muestra que la "patria feliz" era indisociable de un entramado discursivo y emocional que remitía al trabajo y al sacrifico para el bien común, que hacía del dolor una fuente 
de poder, que convertía a la empatía en una cualidad distintiva tanto como en un deber, y que erigía al amor como la emoción clave para esculpir los vínculos entre los integrantes de la comunidad política y emocional peronista. En esta comunidad emocional el cuerpo y la voz de Eva fueron claves. Si las "comunidades imaginadas" de los estados nacionales decimonónicos se apoyaron en los medios de prensa escritos para forjar una comunidad nacional y "racional", y en cierto sentido masculina, la comunidad emocional en la política de masas del siglo XX es impensable sin la voz humana, sin la voz de Eva reproducida, ampliada y preservada por las tecnologías. La "política de las emociones" articuló el vínculo afectivo entre Eva y sus "grasitas" (además de estimular emociones entre los no peronistas), y fue inseparable de expresiones institucionales y de obligaciones legales. La política y las emociones son indisociables también porque, si seguimos a Gould (2010), "las ideas arraigan o no dependiendo de la carga afectiva generada al entrar en contacto con ellas" (p. 33).

Los mártires son recursos culturales tangibles de los que las personas se aprovechan cuando necesitan un objeto simbólico para definir, explicar, galvanizar el curso de la acción. A través del mártir los "emprendedores morales" buscan obtener comportamientos deseados, generar identidades colectivas y persuadir a una audiencia potencialmente indiferente, haciendo tangibles los valores, emociones y creencias que el mártir encarna. Una mirada en el largo plazo sugiere que el martirio de Eva, contemporáneo a la emergencia del peronismo en la política argentina, no perduró como figura aglutinante central una vez que el peronismo fue derrocado en 1955. El sustantivo mártir y su asociación con Eva no desaparecen del todo, por supuesto. Hace serie, también, con muertos posteriores como los peronistas asesinados en el golpe de estado de 1955, en junio de 1956, o con el sufrimiento causado por la proscripción y la resistencia. En las conmemoraciones por el aniversario de su muerte después de 1955 también Eva es invocada como mártir (Ehrlich, 2015), pero en ninguna de estas ocasiones -y más allá de los actores que enarbolaron la figura y de los contextos específicos en que aconteció- su martirio tuvo los sentidos y la centralidad política que tuvo ella hasta 1952. La apropiación que la organización armada peronista Montoneros hizo de Eva en los años 70 del siglo pasado - militante, fanática, implacable, dispuesta al sacrificio personal (Navarro, 1997)- también priorizó valores y emociones diferentes a los que moldearon su figura originaria. Los mártires que poblaron el discurso y las expectativas de las izquierdas y derechas en los años 60 y 70 del siglo XX argentino no se referenciaron en el martirio de ninguna mujer. Quienes murieron torturados o acribillados por la policía daban algo nuevo, y trágico, y diferente, al peronismo y sus mártires. La capacidad de entrega, la renuncia a la vida con las armas en la mano era tan inseparable de la vía revolucionaria como de un modelo de masculinidad en el que el martirio femenino de Eva no tenía lugar. De la multiplicidad de representaciones visuales y sonoras de Evita que recorren el globo desde hace más de una década, la mujer sonriente y hermosa, emancipada, empoderada y preocupada por los pobres es perfectamente compatible tanto con la política como con el entretenimiento. Este impresionante y disímil cultivo de su figura estuvo en manos del peronismo, la mayor parte de la segunda mitad del siglo XX proscripto de la política argentina, pero también de la cultura de masas que muy tempranamente percibió la potencia comercial de esta mujer que se había iniciado públicamente en el mundo del espectáculo (Ehrlich-Gayol, 2018; Guy, 2004). No era necesaria una Eva sufriente y abnegada, dispuesta a sacrificarse para mitigar el dolor y asegurar la felicidad del pueblo. No era necesario predicar la empatía con los pobres y sufrientes. Estos valores y emociones se habían desprendido de su figura de mártir en la que originalmente habían sido incubados, y ya eran parte constitutiva de la discursividad política y emocional peronista. Las revistas de circulación masiva que apelaron a públicos muy diversos en los años 60 recuperan, aunque con variantes, una Eva política y genuinamente comprometida con el bienestar y el dolor de los humildes, pero sin necesidad de su martirio. Esta bella mujer es puesta en serie con "casos" femeninos de la cultura y la política de masas de esos años (como Jacqueline Kennedy, la hija de Stalin o Rita Pavone). Rutilante y moderna, femenina y en algunas representaciones también feminista, siempre sensible a los más vulnerables, fue esta Evita la que también proliferó y predominó en performances, imágenes y narrativas que conmemoraron los 100 años de su nacimiento en 2019. En el decurso del tiempo la figura de la Eva mártir, 
SANDRA GAYOL. LA OTRA CARA DE LA FELICIDAD: DOLOR Y MARTIRIO EN EL PERONISMO CLÁSICO ${ }^{1}$

central en su discursividad y en la del peronismo de los años 40 y 50, parece haberse ajustado al deseo de su propia portadora. Como afirmó en 1948, su misión era "acercar el amor y el gozo del pan al mayor número (y) que sea la risa, la amplia sonrisa de la paz y de la justicia, la contraseña del argentino dentro del mundo”. ${ }^{30}$

\section{REFERENCIAS}

Acha, O. (2013). Crónica sentimental de la argentina peronista. Sexo, inconsciente e ideología (1945-1955). Buenos Aires: Prometeo.

Anderson, B. (2006). Comunidades imaginadas. Reflexiones sobre el origen y difusión del nacionalismo. Buenos Aires: FCE.

Barry, C. (2009). Evita capitana: El Partido Peronista Femenino 1949-1955. Caseros: Ed. UNTREF.

Berhó, D. (2000). Working Politics: Juan Domingo Peron's Creation of Positive Social Identity. Rocky Mountain Review of Language and Literature, 54(2), 65-76.

Bodicce, R. (Ed.) (2014). Pain and Emotion in Modern History. London: Palgrave McMillan.

Bourke, J. (2014). The Story of Pain: From Prayer to Painkillers. Oxford: Oxford University Press.

Caimari, L. (1995). Perón y la Iglesia Católica. Religión, Estado y sociedad en la Argentina (1943-1955). Buenos Aires: Ariel.

Casquette, J. (2009). Martyr Construction and the Politics of Death in National Socialism. Totalitarian Movements and Political Religions, 10(3-4), 265-283, September-December.

Catoggio, M. (2013). The Consecration of Political Suffering: Martys, Heroes and Victims in Argentine Political Culture. Journal of Latin American Studies, 45, 695-719.

DeSoucey, M., Pozner, J., \& Fields, C. (2008). Memory and sacrifice: An embodied theory of Martyrdom. Cultural Sociology, 1(2), 100-121.

de Spiegeleer, Ch. (2014). The blood of martyrs is the seed of progress. The role or martyrdom in socialist death culture in Belgiuem and the Netherlands, 1880-1940. Mortality:promoting the interdisciplinary study of death and dying, 19(2), 184-205.

Ehrick, C. (2015). Radio and the Gendered Soundscape. Women and Broadcasting in Argentina and Uruguay 1930-1950. New York: Cambridge University Press.

Ehrlich, L., y Gayol, S. (2018). Las vidas post-mortem de Eva Perón: cuerpo, ausencia y biografías en las revistas de masas de la Argentina. Historia Crítica, 70, 111-131.

Ehrlich, L (2015). La conmemoración ritual de Eva Perón en la primera década después de su muerte, Buenos Aires y Tucumán (1953-1962). XV Jornadas Inter/escuelas Departamento de Historia. Comodoro Rivadavia, Chubut.

Flattley, J. (2008). Affective mapping. Melancolia and the politics of modernism. Cambridge Massachussets and London. Ed: Harvard University Press.

Frevert, U. (2013). La politique des sentimentess aux XIXè siècle. Revue d'bistoire du XIXe siècle, 46, 51-72.

Gené, M. (2005). Un Mundo feliz. Imágenes de los trabajadores en el primer peronismo 1946-1955. Buenos Aires: Fondo de Cultura Económica.

Gerchunoff, P., y Llach, J. (2008). El ciclo de la ilusión y el desencanto. Políticas económicas argentinas de 1880 a nuestros dias. Buenos Aires: Edhasa.

Gould, D. (2010). On affect and Protest. En Janet Staiger, Ann Cverkovich y Ann Reynold (eds). Political Emotions: New Agendas in Communication. Texas: Routledge-University of Texas, 18-44

Guy, D. (2004). Life and the Commodification of Death in Argentina: Juan and Eva Perón. En L. Johnson (ed.), Body Politicis. Death, dismemberment, and Memory in Latina America (pp. 245-272). Alburquerque: New Mexico.

Guy, D. (2016). Creating Charismatic Bonds in Argentina. Letters to Juan and Eva Perón. Alburquerque: New Mexico. Healey, M. (2012). El peronismo entre las ruinas. El terremoto y la reconstrucción de San Juan. Buenos Aires: Siglo XXI. Illouz, E. (2012).¿Por quéduele el amor? Una explicación sociológica. Buenos Aires: Katz. 
James, D. (1990). Resistencia e integración. El peronismo y la clase trabajadora argentina. Buenos Aires: Sudamericana. James, D. (2004). Doña María. Historia de vida, memoria e identidad politica. Buenos Aires: Manantial.

Karush, T. (2013). Cultura de clase. Radio y cine en la creación de una argentina dividida (1920-1946). Buenos Aires: Ariel.

Navarro, M. (1997). Evita. Buenos Aires: Planeta.

Nussbaum, M. (2008). Paisajes del pensamiento. La inteligencia de las emociones. Barcelona: Paidós.

Nussbaum. M. (2014). Emociones políticas. ¿Por qué el amor es importante para la justicia? Barceloa: Paidós.

Peláez, S., y Valobra, A. (2004). ¡Sea legisladora...! Una aproximación a la representación de las primeras legisladoras nacionales argentinas, 1952-1955. En K. Ramacciotti y A. Valobra (comps). Generando el peronismo. Estudios de cultura, política y género (pp. 89-122). Buenos Aires: Proyecto editorial.

Plamper, J. (2014) Historia de las emociones. Caminos y retos. Cuadernos de Historia Contemporánea, 36, 17-29.

Rein, R., y Panella, C. (2014). La segunda línea: liderazgo peronista, 1945-1955. Buenos Aires: Pueblo HerederoUNTREF.

Reyes, F. (2016). En busca del mito perdido. Los radicales y las conmemoraciones de la revolución de parque, entre la división y la reorganización (1898-1903). En C. Giletta y B. Carrizo (Eds.), VI Congreso Regional de Historia e Historiografia (pp.41-76). Santa Fe: Universidad Nacional del Litoral,.

Rozenwein, B. (2010). Problems and Methods in the History of Emotions. Passions in Context, 1, 1-33.

Sarlo, B. (2003). La Pasión y la excepción. Buenos Aires: Siglo XXI.

Seveso, C. (2010). Political Emotions and the origins of the Peronist Resistance. En M. Karush \& O. Chamosa (eds), The new cultural history of Peronism (pp. 239-269). Durham and London: Duke University Press.

Sigal, S., y Verón. E. (2003). Perón o muerte. Los fundamentos discursivos del fenómeno peronista. Buenos Aires: Eudeba. Testa, D. (2018). Del alcanfor a la vacuna Sabin: la polio en la Argentina. Buenos Aires: Biblos.

Torre, J. C., y Pastoriza, E. (2002). La democratización del bienestar. En J. C. Torre (Ed.), Nueva Historia Argentina. Los Años Peronistas (1943-1955) (pp. 259-310). Buenos Aires: Sudamericana.

Valobra, M. A. (2010). Del hogar a las urnas. Recorridos de la ciudadanía politica femenina Argentina, 1946-1955. Rosario: Prohistoria.

\section{Notas}

1 Agradezco los comentarios de María Bjerg, Laura Ehrlich y de los dos evaluadores anónimos a una versión previa de este artículo.

2 Expresión presente en los discursos de Eva y de Perón, y también en diarios como El Lider o Democracia. En algunos documentos el origen de la frase se le atribuye a Perón.

3 Es imposible reponer aquí las observaciones, respuestas y revisiones de Rosenwein al concepto de "comunidad emocional”. Una idea importante de la autora y útil para mi trabajo es la que sostiene que pueden coexistir más de una "comunidad emocional" y que estas cambian con el tiempo. Rosenwein, especialista en historia medieval, no pudo enfatizar un aspecto que, se advertirá, es clave en la comunidad emocional peronista: el papel de la voz humana y femenina, y su amplificación por las tecnologías propias del siglo XX.

4 Para el objetivo y perspectiva adoptada por este artículo no es relevante la autoría de las palabras que pronunció y usó Eva.

5 Parte de un discurso de Perón pronunciado el 16 de junio de 1948 en Y.P.F. ante legisladores nacionales y dirigentes políticos del partido peronista.

6 Uso politica de las emociones y no politica de los sentimientos, como sería la traducción francesa (politique des sentiments) del texto de Frevert escrito en alemán (Gefülspolitik). El significado de política de las emociones que explícito en el cuerpo central del texto lo tomo en parte de Frevert. Lo uso entrecomillado, pues como indica la autora, es una expresión que emerge en el siglo XIX europeo de la mano de intelectuales y algunos dirigentes políticos. Su connotación en esa época era solo negativa.

7 Democracia, "Cumplir con Evita", 11 de agosto de 1952.

8 Mensaje radial del 27 de enero de 1947.

9 También Moscoso propone que el dolor es una emoción vivencialmente poliédrica y sujeta a evolución (Moscoso, 2011). 
10 Tomo la idea de Bourke que vincula “being in pain” con los dispositivos, en términos de Foucault, esto es: leyes, discursos, instituciones, estructuras médicas, científicas, históricas, filosóficas, que sustentan, respaldan, apuntalan conocimientos y conductas asociadas con being in pain. (Bourke, 2014).

11 Escúchese por ejemplo el discurso de navidad que transmitió la Radio del Estado el 26 de diciembre de 1946.

12 Las cursivas son del original.

13 Extraído del discurso pronunciado por Eva el 21 de enero de 1949 en el Luna Park. Fue un acto de homenaje a ella y a Perón organizado por el gremio metalúrgico. La cursiva me pertenece.

14 Estaba en sintonía con el discurso de Perón, quien también criticó a los consumidores argentinos por vivir más allá de sus posibilidades.

15 La voz de Eva como uno de sus rasgos más distintivos, y memorables, aparece puesta en valor en numerosas notas de pésame que la población escribió y envió al gobierno en ocasión de su muerte.

16 Parte de un discurso pronunciado el 10 de septiembre de 1951.

17 "Últimas palabras", en Mundo Peronista, Año II, N.26, agosto 1, 1952.

18 Para las trayectorias de algunos legisladores (Rein y Panella, 2014). Sobre la trayectoria de 18 mujeres legisladoras (Valobra, 2010).

19 Expresión del diputado por Santa Fe, Corbelli, p. 173. Sesión en diputados 5/6/52. Todas las intervenciones son extraídas de los discursos parlamentarios que figuran en las actas del Congreso de la Nación. Se cita al autor de la intervención y el número de página tal como aparece en las actas.

20 Sobre cómo entendieron la representación las mujeres: Peláez, Sol y Valobra, Adriana, 2004.

21 La primera expresión pertenece al diputado por la Capital Sr. Rumbo, la segunda al diputado Agüero por Catamarca, p. 208 y 2016 respectivamente. Sesión 18/6/52.

22 Sesión del 18/6/52

23 Sesión 19/6/52, p. 225.

24 Sesión 25/6/52, p. 247.

25 Senador Albariños por Entre Ríos, Sesión 3/7/52, p. 172.

26 Senador por la capital Miel Asquía, Sesión 4/7/52, p. 199.

27 Tomo esta idea de justicia de Nussbaum Martha (2014), p. 20.

28 Diputado por Catamarca Sr. Agüero, Sesión 18/6/52, pp. 216-217.

29 Diputada Dacunda, Sesión 18/6/52.

30 El párrafo es parte del discurso pronunciado en Santa Fe, el 6 de diciembre de 1948, en el marco de su participación en la campaña electoral por la renovación de diputados nacionales.

\section{BY-NC-SA}

